\title{
Microbiome and metabolic changes in milk in response to artemisinin supplementation in dairy cows
}

Kun Hou ${ }^{1+} \mathbb{D}$, Jinjin Tong ${ }^{1 *+}$, Hua Zhang ${ }^{1 \dagger}$, Shan Gao ${ }^{1}$, Yuqin Guo ${ }^{1}$, Hui Niu' ${ }^{1}$, Benhai Xiong ${ }^{2}$ and Linshu Jiang ${ }^{1 *}$

\begin{abstract}
This study aimed to explore the effects of artemisinin (ART) on the milk microbiome and metabolites of dairy cow. A total of 12 mid-lactation Holstein dairy cows with similar parity, days in milk were randomly divided into 2 groups receiving either a total mixed ration (TMR) as the control group or this TMR and $120 \mathrm{~g} / \mathrm{d} / \mathrm{head}$ ART as the ART group. The milk samples were collected weekly to determine the contents, and end-of-trial (week 8) milk samples were used to identify microbial species and metabolite profiles by 16 S rRNA sequencing and LC-MS analyses, respectively. We observed that the milk fat content significantly increased by ART treatment $(P<0.05)$. The bacterial community richness was significantly lower in the ART group $(P<0.05)$, while the diversity showed no difference $(P>0.05)$. Compared with its abundance in the control (CON) group, Firmicutes was significantly decreased, whereas Proteobacteria was significantly increased. Furthermore, in the ART group, the relative abundances of the genera Aerococcus, Staphylococcus, Corynebacterium_1 and Facklamia were significantly lower $(P<0.01)$. Metabolomics analysis revealed that ART significantly increasing the concentrations of glycerophospholipids, glycerolipids and flavonoids compared with those in the CON group. An enrichment analysis of the different metabolites showed that ART mainly affected glycerophospholipid metabolism and the pantothenate and CoA biosynthesis pathways. These findings revealed that ART supplementation could affect the milk microbiota and metabolites, that glycerophospholipids and glycerolipids could be potential biomarkers in the milk response to ART feed in dairy cows, and that ART changes substances in milk by maintaining lipid metabolism in the mammary gland.
\end{abstract}

Keywords: Microbiome, Metabolomics, Artemisinin, Milk, Dairy cows

\section{Introduction}

Milk serves not only as an important medium for nutrition but also as an indicator of the metabolic status of dairy cows. Insights from recent investigations of milk biosynthesis suggest that the microbiota can provide a great reference for the evaluation of milk quality (Guan et al. 2014). Members of the milk microbiota could directly affect the quality of milk, such as lactic acid bacteria, Lactobacillus, and Lactococcus (Guan et al. 2014;

\footnotetext{
*Correspondence: tongjinjin0451@163.com; jls@bac.edu.cn

${ }^{\dagger}$ Kun Hou, Jinjin Tong and Hua Zhang contributed equally to this work

${ }^{1}$ Beijing Key Laboratory for Dairy Cow Nutrition, Beijing University

of Agriculture, Beijing 102206, People's Republic of China

Full list of author information is available at the end of the article
}

Vanderhaeghen et al. 2014; Ganda et al. 2017). In particular, some specific dominant bacteria play an important role in udder homeostasis, which guarantees high milk quality (Tong et al. 2019).

To a certain extent, microbial diversity and richness reflect the mammary gland health of dairy cows (Guan et al. 2014), and there is an interesting report of the udder microbiota having a lower diversity in quarters with a history of clinical mastitis than in healthy quarters (Hélène et al. 2016). Additionally, 16S rRNA sequencing technology has become an important technique to study the composition and structure of sample microbial communities (Caporaso et al. 2011). Through comparison with databases, the diversity of the milk microbiome was analyzed with high speed, high flux and high accuracy
Springer Open (c) The Author(s) 2020. This article is licensed under a Creative Commons Attribution 4.0 International License, which permits use, sharing, adaptation, distribution and reproduction in any medium or format, as long as you give appropriate credit to the original author(s) and the source, provide a link to the Creative Commons licence, and indicate if changes were made. The images or other third party material in this article are included in the article's Creative Commons licence, unless indicated otherwise in a credit line to the material. If material is not included in the article's Creative Commons licence and your intended use is not permitted by statutory regulation or exceeds the permitted use, you will need to obtain permission directly from the copyright holder. To view a copy of this licence, visit http://creativeco mmons.org/licenses/by/4.0/. 
(Kuehn et al. 2013). In particular, the udder commensal mammary microbiota has recently attracted much attention to the milk microbiota differences between the colostrum and milk from healthy quarters or mastitis quarters of dairy cows (Guan et al. 2014; Hélène et al. 2016). In addition, the administration of antibiotics for mastitis treatment and antimicrobial resistance also reveal the effects of the milk microbiome response to udder defense mechanisms as determined by $16 \mathrm{~S}$ rRNA sequencing or metagenomic investigations (Ganda et al. 2017).

With variations in the microbial community structure in milk, metabolites also change. Milk quality is regulated by different metabolic pathways, resulting in differences in milk production and nutrients such as fat, protein, and lactose. Furthermore, a complex array of bioactive molecules such as immunoglobulins, lysozyme, and lactoferrin are the major immunoregulatory components of milk (Korhonen et al. 2000). Metabolomics has received much attention because it can amplify tiny changes in gene and protein expression at the metabolite level and more fully reflect the functional level of cells than other techniques can (Mansor 2012). In addition, metabolomics is also used to quantitatively measure metabolic status in milk, including the levels of metabolic biomarkers during lactation (Sun et al. 2017a), alterations in metabolites resulting from mastitis (Tong et al. 2019), and changes in metabolic profiles resulting from antibiotic treatment (Junza et al. 2016). Nontarget metabolic techniques based on liquid chromatography/mass spectrometry (LC-MS) could identify a large number of complete metabolites with the advantages of high flux and high sensitivity (Gowda and Djukovic 2013). Therefore, LCMS can provide a comprehensive overview of changes in milk metabolites in response to artemisinin supplementation in dairy cows.

Artemisinin (ART), a sesquiterpene lactone with a peroxy-bridge structure, has multiple actions including antibacterial, anti-inflammatory, antitumor and antiviral pharmacological effects (Shi et al. 2015). Because of its effectiveness as an anti-malarial drug, artemisinin was labeled as "the greatest hope for treating malaria" by the WHO, and Chinese scientist Tu You-you won the Nobel Prize in Physiology or Medicine in 2015 for her discoveries. Moreover, artemisinin has great potential in the poultry industry. Previous studies have shown that adding appropriate amounts of ART or its derivatives to the diet improved the performance of laying hens, increased egg weight and yolk color and had anticoccidial effects (Brisibe et al. 2008). In addition, ART can effectively alleviate declines in broiler performance caused by heat stress and reduce intestinal inflammation (Song et al. 2017). ART feeding trials have shown promising bacteriostatic activity especially with regard to its potential role in the bovine rumen which houses a complex microbiota and plays an important role in digestion. However, the application of ART in dairy farming has rarely been reported. We hypothesized that ART would affect dairy cow performance and trigger changes in milk microbiota and metabolites, providing a theoretical basis of traditional Chinese herbal medicine for animal welfare.

Our goal was to appraise the effects of ART on the performance and milk microbial diversity and metabolites of dairy cows. We aimed to explore the changes in the species composition of the milk microbial profile by using $16 \mathrm{~S}$ rRNA sequencing and to detect the metabolites in milk by untargeted metabolic techniques. We also identified correlations between the milk microbiota and metabolites by ART supplementation.

\section{Materials and methods}

The Artemisia апnua extract (brown powder form) used in these experiments was purchased from Shaanxi Sciphar Natural Products Co., Ltd. (Shanxi, China). The active ingredients in the Artemisia annua extract were analyzed by UV spectroscopy, resulting in the following contents: ART $39 \%$, crude ash $5 \%$, crude fiber $27.9 \%$, crude protein $6.3 \%$, water $5 \%$, ash $8.0 \%$, polysaccharide $8.3 \%$ and volatile oil $0.5 \%$ (Additional file 1).

\section{Animals and experimental design}

All experimental procedures were approved by the Animal Care Committee, Beijing University of Agriculture (Beijing, China). A feeding experiment was performed in a commercial dairy farm in Yanqing District, Beijing. Twelve lactating Chinese Holstein dairy cows with similar weight $(590 \pm 15.5 \mathrm{~kg} ; P=0.96)$, parity $(3.65 \pm 0.78$; $P=0.82)$, days in milk $(183.2 \pm 16.8 \mathrm{~d} ; P=0.65)$, and milk yield $(30.47 \pm 3.23 \mathrm{~kg} / \mathrm{d} ; P=0.88)$ were selected and divided into two groups. The cows were fed either a total mixed ration (TMR) as the control group $(\mathrm{CON}, \mathrm{n}=6)$ or this TMR with ART supplementation of $120 \mathrm{~g} / \mathrm{d} / \mathrm{head}$ (ART, $n=6$ ). The ART dosage for dairy cows used in the present study was based on the dosage from an in vitro study and an in vivo study in dairy cows (Xue et al. 2004; Hou et al. 2019). The animals were housed individually in stalls bedded with sawdust, feed was available for ad libitum consumption, and free access to water was given. The ingredients and nutrient composition of the TMR were presented in Table 1. Feeding and milking occurred 3 times per day (07:00, 14:00 and 20:00). The experiment lasted for 8 weeks, with 2 weeks for feeding with the TMR and 6 weeks of treatments. Milk samples were collected weekly, and production was recorded at each milking. A total of $15 \mathrm{ml}$ of composite milk from each animal, with approximately equal volumes from each lactating 
Table 1 Composition and nutrient levels of the basal diet

\begin{tabular}{|c|c|}
\hline Item & Content, $\%$ \\
\hline \multicolumn{2}{|l|}{ Ingredient } \\
\hline Ground corn & 9.58 \\
\hline Corn silage & 46.62 \\
\hline Corn bran & 3.70 \\
\hline Steam-flaked corn & 4.40 \\
\hline Alfalfa hay & 6.90 \\
\hline Oat grass & 2.50 \\
\hline Soybean meal & 5.00 \\
\hline Dried distiller grains with solubles (DDGS) & 4.40 \\
\hline MEGALAC & 0.90 \\
\hline Extruded soybean & 3.00 \\
\hline Barley & 2.76 \\
\hline Wheat bran & 2.76 \\
\hline Sodium cyclamate & 2.20 \\
\hline Oats & 1.30 \\
\hline Canola meal & 1.17 \\
\hline Cottonseed meal & 1.17 \\
\hline $\mathrm{NaHCO}_{3}$ & 0.59 \\
\hline Limestone & 0.48 \\
\hline $\mathrm{NaCl}$ & 0.27 \\
\hline Premix ${ }^{b}$ & 0.30 \\
\hline \multicolumn{2}{|l|}{ Chemical composition $^{c}$} \\
\hline Crude protein (CP) & 18.4 \\
\hline Neutral detergent fiber (NDF) & 31.1 \\
\hline Acid detergent fiber (ADF) & 15.6 \\
\hline Ether extract & 5.00 \\
\hline $\mathrm{Ca}$ & 0.77 \\
\hline$P$ & 0.43 \\
\hline $\mathrm{NE}_{\mathrm{L}^{\prime}}, \mathrm{Mcal} / \mathrm{kg}$ & 1.76 \\
\hline
\end{tabular}

a Church and Dwight Co., Inc., Princeton, NJ, USA

b Formulated to provide (per kg of DM) 4,560 mg of $\mathrm{Cu}, 3,000 \mathrm{mg}$ of $\mathrm{Fe}$, $12,100 \mathrm{mg}$ of $\mathrm{Zn}, 4,590 \mathrm{mg}$ of $\mathrm{Mn}, 60 \mathrm{mg}$ of $\mathrm{Co}, 200 \mathrm{mg}$ of Se, $270 \mathrm{mg}$ of I, 10,000 IU of vitamin $E, 450,000$ IU of vitamin D, 2,000,000 IU of vitamin A, and $3,000 \mathrm{mg}$ of nicotinic acid

c Chemical composition based on chemical analysis of the total mixed ration (TMR), as described

udder quarter, was transferred to a sterile plastic bottle (Corning Inc., Corning, NY, United States), kept on ice until transport to the laboratory and then stored at $-80{ }^{\circ} \mathrm{C}$ for further analysis.

\section{Milk sampling and analyses}

The daily milk production was recorded during the experiment. The somatic cell count (SCC) in milk was detected by a somatic cell counting instrument (Fossomatic 5000, FOSS, Denmark). The milk fat rate, milk protein rate and milk lactose rate were determined by a milk composition analyzer (Bentley Instruments, Chaska, $\mathrm{MN})$. Milk samples were collected weekly to measure the contents, and the end-of-trial (week 8) milk samples were used to identify the microbial species and metabolite profiles by $16 \mathrm{~S}$ rRNA gene sequencing and LC-MS, respectively. All the samples were stored in liquid nitrogen for further analysis.

\section{S rRNA high-throughput sequencing analysis}

Genomic DNA extraction for 12 milk samples was performed using a Power Soil DNA Isolation Kit (Qiagen, Crawley, United Kingdom) following the manufacturer's instructions. The concentration of DNA was determined by spectrophotometry, and the purity of DNA was estimated according to the ratio of the UV absorption values of DNA at $260 \mathrm{~nm}$ and $280 \mathrm{~nm}$ (OD260/OD280). Amplicon libraries covering the V3-V4 hypervariable regions of the microbial $16 \mathrm{~S}$ rDNA gene were amplified using the primers $341 \mathrm{~F}\left(5^{\prime}\right.$-ACTCCTACGGGRSGCAGCA G-3') and 806R (5'-GGACTACVV GGGTATCTAATC $\left.-3^{\prime}\right)$. The reactions were performed on a thermocycler (GeneAmp 9700, ABI, USA). PCR amplification products were further purified by the AxyPrep DNA Gel Extraction Kit (Axygen Biosciences, Union City, CA, USA) and then quantified using QuantiFluor ${ }^{\mathrm{TM}}$-ST (Promega, USA). Finally, high-throughput sequencing analysis of bacterial rRNA genes was performed on purified pooled samples using the Illumina HiSeq platform (Illumina, San Diego, CA, USA) for paired-end reads of $300 \mathrm{bp}$ at Majorbio Bio-Pharm Technology Co. Ltd. (Shanghai, China) according to standard protocols.

\section{Sequence processing and analysis}

Analyses were conducted with FLASH version 1.2.11 and Quantitative Insights into Microbial Ecology (QIIME) ver 1.9.1. These versions gave similar data(Tong et al. 2019). The reads were clustered as operational taxonomic units (OTUs) by scripts in USEARCH (ver 7.1) with a 97\% similarity threshold(Edgar, 2013). The OTU sequences were categorized by taxa by BLAST in the Ribosomal Database Project Classifier (ver 2.2) and Silva (SSU123) 16S rRNA database. OTUs were normalized to relative abundance and bacterial composition was determined by Majorbio I-Sanger.

Within-sample diversity (alpha diversity) was assessed through bacterial community enrichment (ACE and Chao indices) and diversity (Shannon and Simpson indices) that were measured in a stochastic subset of the OTUs. Between-sample microbial diversity (beta diversity) was measured by phylogenetically-based weighted UniFrac distances (Wang et al. 2018). The predominant clades in the milk microbiome were acquired by filtering OTUs for those with relative abundance of $\geq 1 \%$ one or more samples. 


\section{Nucleotide sequence accession number}

All raw sequences were submitted to the NCBI Sequence Read Archive (SRA: http://www.ncbi.nlm. nih.gov/Traces/sra/) under accession number SRP 254006.

\section{Metabolomics analysis}

Milk samples were analyzed for specific components using an LC-MS platform (Thermo, Ultimate 3000 LC, Q Exactive), and sample preparation was performed as per our previously published procedure (Wang et al. 2018; Tong et al. 2019). The following steps were conducted by Majorbio Bio-Pharm Technology Co., Ltd. Analysis of metabolomics data was performed with Progenesis QI (Waters Corporation, Milford, USA) to match MS and MS/MS mass spectrum information with that in the metabolism database. The retention time (RT), $\mathrm{m} / \mathrm{z}$, observation data (samples) and peak intensity were normalized using Microsoft Excel 2017. Screened differential metabolites were characterized using the https:// metlin.scripps.edu/public database, a self-built database for the Majorbio I-Sanger Cloud Platform (www.i-sange r.com) and KEGG pathway analysis (www.metaboanalyst. $\mathrm{ca} /)$.

\section{Multivariate statistical analysis}

Statistical comparisons were evaluated using Student's $t$ test. A $P$ value of $<0.05$ was defined as statistically significant. Hierarchical clustering was conducted using the similarity index of Bray-Curtis by the UPGMA. The strengths of correlations between metabolites and milk bacterial species were estimated using Spearman correlation coefficients and visualized by using the $\mathrm{R}$ language (Kolde 2015). A $P$ value $<0.05$ was defined as statistically significant. The statistical analyses were performed with SPSS software version 21.0 (IBM, Armonk, NY). The alpha diversity indexes are presented as the mean \pm SEM. Principal coordinate analysis (PCoA) and orthogonal partial least-squares-discriminant analysis (OPLS-DA) were performed to visualize the metabolic differences between the experimental groups after mean centering and unit variance scaling. Variables with variable importance in the projection (VIP) values exceeding 1.0 were considered relevant for group discrimination. In this study, the OPLS-DA model was validated with sevenfold permutation tests. Significant differences in metabolites between groups were assessed using Wilcoxon rank-sum tests.

The original milk composition data were analyzed by Excel 2017, and statistical comparisons were evaluated using one-way ANOVA in SPSS 21.0 was used (IBM Corp., Armonk, NY, USA). Differences were considered statistically significant when $P<0.05$ and a trend when $P<0.10$.

\section{Results \\ Effects of ART on milk performance}

As shown in Table 2, the milk yield tended to increase $(P=0.06)$, and the fat yield $(P=0.04)$ was increased by ART supplementation at the end of the trial. Milk lactose and protein were not different in the two treatment groups. Milk fat content was greater in the ART group than in the CON group $(P=0.04)$, and the fat/protein ratio was also increased $(P=0.03)$. In addition, the SCC tended to be decreased $(P=0.08)$ with ART supplementation compared with the CON treatment.

\section{Microbiota diversity analysis}

In total, 757,666 high-quality sequences for 12 samples were analyzed after the sequences passed quality control, which resulted in an average read length of $311 \mathrm{bp}$, and there was $>99 \%$ depth coverage. This result showed that the data were reasonable and could reflect the changes in most bacterial flora. Furthermore, the rarefaction curves for most of the samples plateaued, which further confirmed the sufficiency of the data. The alpha diversity index results for the groups are shown in Table 3. According to the ACE and Chao indexes, which represent the bacterial community richness, there was a significant difference between the CON and ART groups, with lower richness in the ART group $(P<0.05)$. However, the bacterial diversity (Shannon and Simpson indexes) was similar between the two groups.

Table 2 Effect of dietary addition of ART on milk production and composition in dairy cows

\begin{tabular}{lrrrl}
\hline Item & CON & ART & SEM & P value \\
\hline Yield, kg/d & & & & \\
Milk & 30.23 & 31.22 & 0.91 & 0.06 \\
ECM $^{1}$ & 30.50 & 32.42 & 1.03 & 0.14 \\
Lactose & 1.52 & 1.55 & 0.06 & 0.12 \\
Fat & 1.01 & 1.12 & 0.09 & 0.04 \\
Protein & 0.95 & 0.96 & 0.03 & 0.82 \\
Milk composition, \% & & & & \\
Lactose & 5.03 & 4.97 & 0.04 & 0.16 \\
Fat & 3.31 & 3.58 & 0.18 & 0.04 \\
Protein & 3.15 & 3.07 & 0.22 & 0.41 \\
Fat/protein ratio & 1.05 & 1.16 & 0.13 & 0.03 \\
SCC $\left(\times 10^{4}\right.$ cells/ml) & 12.77 & 10.35 & 0.32 & 0.08 \\
\hline
\end{tabular}

1 ECM $(\mathrm{kg} / \mathrm{d})=0.3246 \times$ milk yield $(\mathrm{kg} / \mathrm{d})+13.86 \times$ fat yield $(\mathrm{kg} / \mathrm{d})+7.04 \times$ protein yield $(\mathrm{kg} / \mathrm{d})($ Orth 1992$)$ 
Table 3 Effect of ART on alpha diversity indexes of milk

\begin{tabular}{lrrrr}
\hline Index & \multicolumn{1}{l}{ CON } & \multicolumn{1}{l}{ ART } & \multicolumn{1}{l}{ SEM } & $\boldsymbol{P}$ value \\
\hline ACE & 2335.08 & 1956.18 & 105.59 & 0.04 \\
Chao & 2258.71 & 1805.37 & 92.79 & 0.02 \\
Simpson & 0.05 & 0.08 & 0.01 & 0.35 \\
Shannon & 4.75 & 4.41 & 0.13 & 0.48 \\
Coverage & 0.99 & 0.99 & 0.01 & 0.21 \\
\hline
\end{tabular}

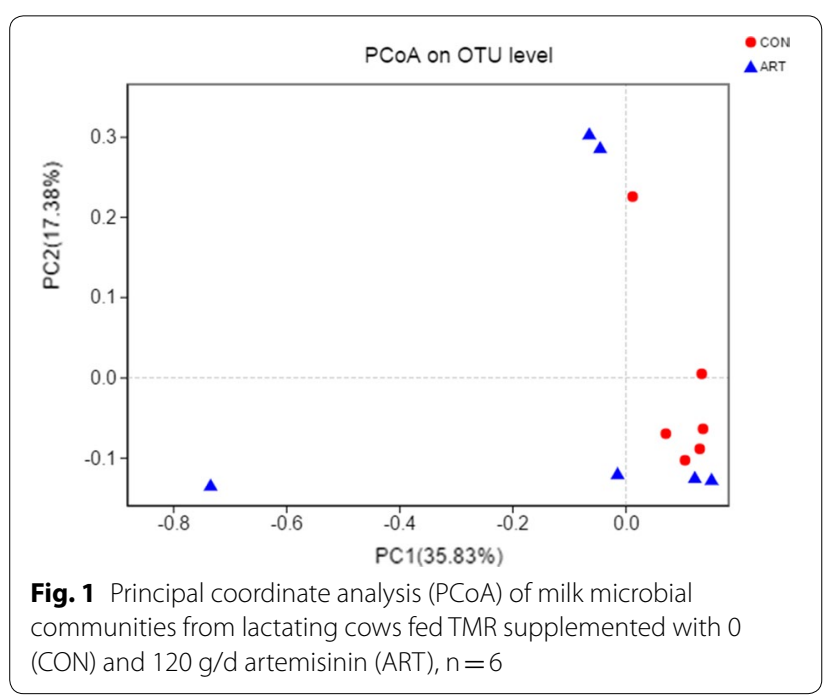

Principal coordinate analysis (PCoA) using weighted UniFrac metrics was performed to visually analyze the similarity or difference in microbial composition in the different groups (Fig. 1). The principal coordinates PC1 and $\mathrm{PC} 2$ accounted for $35.83 \%$ and $17.83 \%$ of the total variance, respectively. This result reflects the microflora being remarkably distinct between the two groups, and the sample points for each group were relatively close.

The results showed a change in the relative abundance of bacteria in milk samples, with the phylum Firmicutes being significantly decreased in the ART group $(P<0.01)$, whereas the relative abundance of Proteobacteria was higher $(P<0.01)$ in the ART group than in the CON group (Fig. 2a, c). At the genus level, the top 10 most abundant bacterial taxa were presented for the two groups (Fig. 2b, d). The ART group had significantly lower relative abundances of Corynebacterium_1 $(P<0.05)$, Aerococcus $(P<0.01)$, Staphylococcus $(P<0.01)$ and Facklamia $(P<0.05)$ than the CON group.

The LEfSe analysis revealed significant increases in Firmicutes and Gracilibacteria and reductions in Proteobacteria, Gammaproteobacteria, unclassified-k-norank-d-Bacteria, $p$-unclassified-k-norank-d-Bacteria and
Alphaproteobacteria in the CON group compared to the ART group (Fig. 3).

\section{Identification of different milk metabolites between CON vs ART}

We next employed LC-MS to characterize the milk metabolome after feeding with ART. In total, 922 measurable peaks were obtained across all the milk samples. The multivariate analysis method OPLS-DA, as shown in Table 4, identified 35 significantly differential metabolites obtained from the milk samples between the ART and CON groups using VIP $>1$ and $P<0.05$. These differential metabolites are primarily glycerophospholipids, flavonoids, organooxygen compounds, fatty acyls, and glycerolipids. Milk from cows receiving ART contained higher levels of glycerophospholipids, prenol lipids, glycerolipids, flavonoids, organooxygen compounds, carboxylic acids and their derivatives and vitamins than did CON cows. In particular, the 4 glycerophospholipid metabolites phosphatidylserine $(\mathrm{PS})(18: 1(9 \mathrm{Z}) / 18: 1(9 \mathrm{Z})), \quad \mathrm{PS}(14: 1(9 \mathrm{Z}) / 22: 1(11 \mathrm{Z}))$, PS(18:0/18:3(9Z,12Z,15Z)), and phosphatidylethanolamine (PE)(P-16:0/20:4(5Z,8Z,10E,14Z)(12OH[S])), 3 flavonoid metabolites and 2 other glycerolipid metabolites (MG(0:0/14:0/0:0) and 1-monopamitin) were elevated. In addition, carboxylic acids and their derivatives and vitamins were present at higher levels in the ART group than in the CON group.

For further analysis, PCA and OPLS-DA were conducted with the CON and ART groups. As shown in Fig. 4a, axes 1 and 2 from PCA accounted for $20.8 \%$ and $17.1 \%$ of the total variation, respectively. The PLS-DA sore plots showed that the milk samples between groups were readily separable. For all the milk samples in the 95\% Hotelling $\mathrm{T}^{2}$ ellipse, axes 1 and 2 from OPLS-DA accounted for $18.5 \%$ and $20.8 \%$ of the variation, respectively. Thus, the CON group and ART group metabolites have different compositions, indicating that PCA and OPLS-DA results reflected the difference in milk metabolites between the two groups well.

\section{Metabolic pathway analysis}

The differential metabolites between the CON and ART groups were analyzed using KEGG pathways for functional enrichment analysis. The significantly changed pathways are shown in Table 5. Lipid metabolism, amino acid metabolism, carbohydrate metabolism, metabolism of cofactors and vitamins, metabolism of terpenoids and polyketides, and digestive system were found to be different between the two groups. Figure 5 shows that 4 metabolic pathways were enriched $(P<0.05)$ : glycerophospholipid metabolism, pantothenate and CoA biosynthesis, linoleic acid metabolism and beta-alanine 

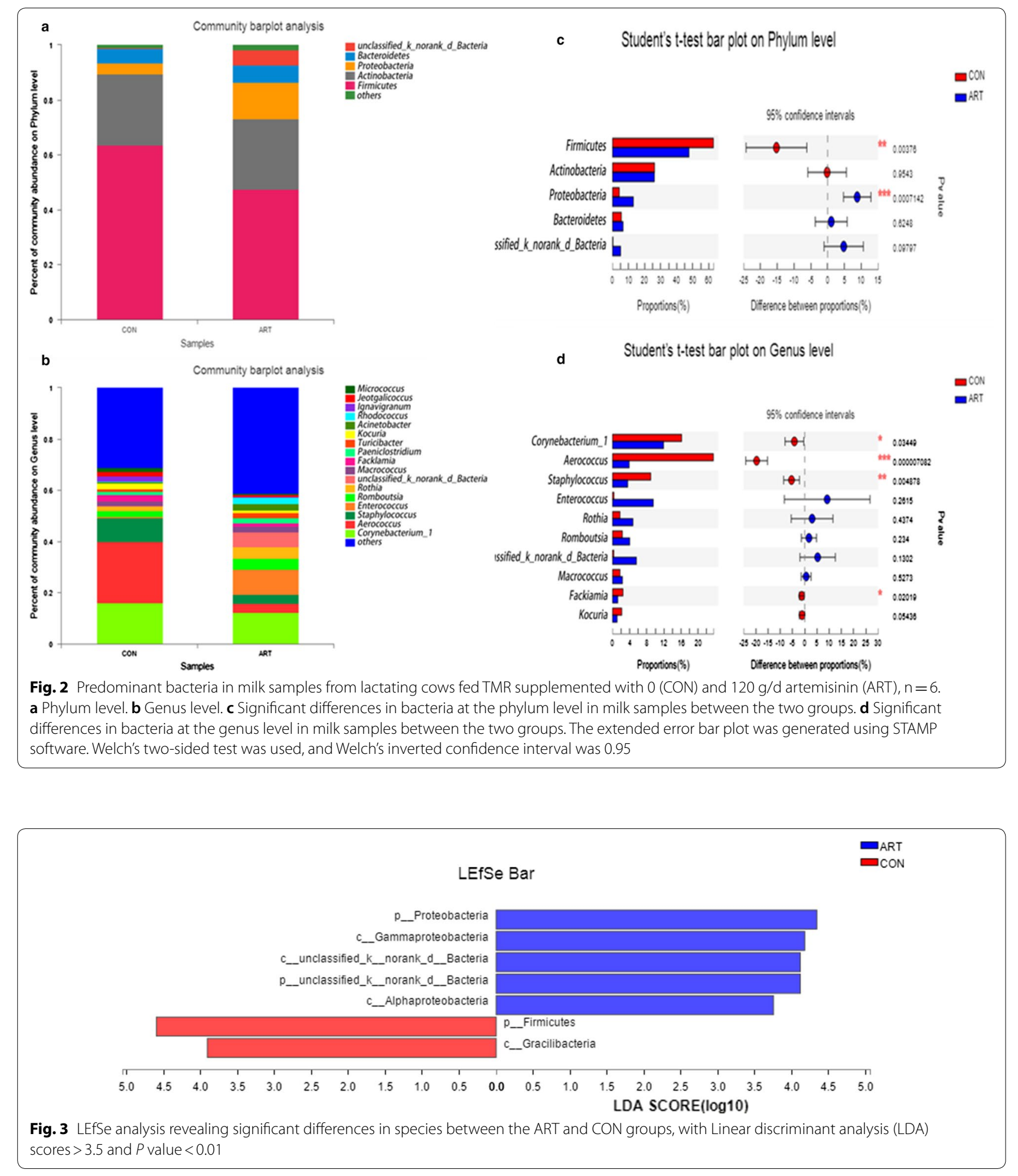

metabolism. Comprehensive $P$ value analysis of pathways revealed that glycerophospholipid metabolism was the pathway with the greatest difference between the ART group and the $\mathrm{CON}$ group.

\section{Correlations between the milk microbiome and metabolites}

Figure 6 shows the genus-level Spearman's correlation coefficients for the milk microbiota and the altered 
Table 4 Identification of significant differential metabolites in milk from lactating cows fed TMR supplemented with 0 (CON) and $120 \mathrm{~g} / \mathrm{d}$ artemisinin (ART), $\mathrm{n}=6$

\begin{tabular}{|c|c|c|c|c|c|c|c|}
\hline Metabolites & $\mathrm{RT}(\min )$ & $\operatorname{lon}(\mathrm{m} / \mathrm{z})$ & Mass error (ppm) & VIP ${ }^{a}$ & $\mathrm{FC}^{\mathbf{b}}$ & $P$ value & Tendency \\
\hline \multicolumn{8}{|l|}{ Glycerophospholipids } \\
\hline$P C(18: 0 / 20: 4(5 Z, 8 Z, 11 Z, 14 Z))$ & 11.09 & 854.59 & 0.85 & 3.69 & 0.55 & 0.00 & \\
\hline PC(16:0/20:4(5Z,8Z,11Z,14Z)) & 10.62 & 826.56 & 1.16 & 5.75 & 0.70 & 0.01 & \\
\hline$P C(16: 0 / 22: 5(4 Z, 7 Z, 10 Z, 13 Z, 16 Z))$ & 10.59 & 852.58 & 0.71 & 4.56 & 0.75 & 0.01 & \\
\hline LysoPC(18:0) & 8.81 & 568.36 & -1.76 & 5.10 & 0.69 & 0.03 & \\
\hline $\operatorname{PS}(20: 5(5 Z, 8 Z, 11 Z, 14 Z, 17 Z) / 18: 2(9 Z, 12 Z))$ & 10.46 & 850.49 & 0.79 & 1.01 & 0.76 & 0.01 & \\
\hline $\operatorname{PS}(18: 1(9 Z) / 18: 1(9 Z))$ & 11.34 & 786.53 & 0.41 & 12.54 & 1.23 & 0.01 & $\uparrow$ \\
\hline PS(18:1(9Z)/22:6(4Z,7Z,10Z,13Z,16Z,19Z)) & 11.15 & 878.52 & 2.88 & 1.15 & 0.71 & 0.00 & \\
\hline PS(18:2(9Z,12Z)/22:6(4Z,7Z,10Z,13Z,16Z,19Z)) & 10.98 & 866.47 & -7.84 & 1.31 & 0.72 & 0.00 & \\
\hline $\operatorname{PS}(18: 2(9 Z, 12 Z) / 18: 0)$ & 10.90 & 808.51 & 0.90 & 1.69 & 0.92 & 0.05 & \\
\hline 1-Stearoylglycerophosphoinositol & 8.50 & 599.32 & -0.76 & 8.73 & 0.68 & 0.01 & \\
\hline$P G(16: 0 / 0: 0)$ & 7.98 & 483.27 & -2.21 & 1.04 & 0.56 & 0.04 & \\
\hline PS(14:1(9Z)/22:1(11Z)) & 11.46 & 788.54 & -1.06 & 9.17 & 1.28 & 0.01 & $\uparrow$ \\
\hline PS(18:0/18:3(9Z,12Z,15Z)) & 10.96 & 786.53 & -1.30 & 4.74 & 1.24 & 0.05 & $\uparrow$ \\
\hline $\mathrm{PE}(\mathrm{P}-16: 0 / 20: 4(5 \mathrm{Z}, 8 \mathrm{Z}, 10 \mathrm{E}, 14 \mathrm{Z})(12 \mathrm{OH}[\mathrm{S}]))$ & 10.52 & 740.52 & -0.51 & 5.81 & 1.22 & 0.01 & $\uparrow$ \\
\hline $\operatorname{PS}(18: 0 / 18: 2(9 Z, 12 Z))$ & 7.03 & 752.51 & -9.59 & 2.53 & 0.18 & 0.03 & \\
\hline \multicolumn{8}{|l|}{ Fatty acyls } \\
\hline Kojibiose & 0.59 & 377.08 & 0.24 & 17.75 & 0.86 & 0.03 & \\
\hline DL-2-hydroxy stearic acid & 9.25 & 299.26 & -2.06 & 1.49 & 0.73 & 0.00 & \\
\hline 2-Methylbutyroylcarnitine & 2.25 & 246.17 & 0.10 & 5.41 & 0.64 & 0.03 & \\
\hline \multicolumn{8}{|l|}{ Prenol lipids } \\
\hline Spirolide E & 7.05 & 708.49 & 7.07 & 2.85 & 0.20 & 0.04 & \\
\hline \multicolumn{8}{|l|}{ Sphingolipids } \\
\hline $\mathrm{SM}(\mathrm{d} 18: 1 / 14: 0)$ & 10.37 & 719.53 & -0.30 & 4.85 & 1.20 & 0.02 & $\uparrow$ \\
\hline \multicolumn{8}{|l|}{ Glycerolipids } \\
\hline MG(0:0/14:0/0:0) & 8.08 & 285.24 & -0.34 & 3.20 & 2.67 & 0.01 & $\uparrow$ \\
\hline 1-Monopalmitin & 8.78 & 331.28 & 0.40 & 2.32 & 1.73 & 0.02 & $\uparrow$ \\
\hline \multicolumn{8}{|l|}{ Imidazopyrimidines } \\
\hline Adenine & 12.99 & 136.06 & -0.28 & 1.45 & 0.61 & 0.00 & \\
\hline \multicolumn{8}{|l|}{ Flavonoids } \\
\hline Isovitexin 7-(6'"-sinapoylglucoside) $4^{\prime}$-glucoside & 0.76 & 943.26 & 6.16 & 3.83 & 3.81 & 0.02 & $\uparrow$ \\
\hline $2^{\prime \prime}-\left(6^{\prime \prime}-p\right.$-Coumaroylglucosyl)quercitrin & 0.80 & 777.16 & -4.81 & 6.15 & 0.42 & 0.01 & \\
\hline 6"-p-Coumaroylprunin & 0.78 & 601.14 & 8.40 & 4.34 & 2.52 & 0.04 & $\uparrow$ \\
\hline Kaempferol 3-(2"-rhamnosylgalactoside) 7-rhamnoside & 0.60 & 777.16 & -5.28 & 4.62 & 0.21 & 0.00 & \\
\hline Kaempferol 3-neohesperidoside-7-(2"-p-coumaryllaminaribioside) & 1.15 & 533.16 & -4.04 & 3.86 & 1.28 & 0.02 & $\uparrow$ \\
\hline \multicolumn{8}{|l|}{ Organooxygen compounds } \\
\hline 3-Glucosyl-2,3',4,4',6-pentahydroxybenzophenone & 0.59 & 445.07 & -8.72 & 1.99 & 0.25 & 0.00 & \\
\hline Maltose & 0.59 & 341.11 & -3.21 & 7.52 & 1.18 & 0.00 & $\uparrow$ \\
\hline N-Acetylgalactosamine & 0.64 & 244.08 & -1.27 & 1.94 & 0.60 & 0.04 & \\
\hline \multicolumn{8}{|l|}{ Carboxylic acids and derivatives } \\
\hline 5-Aminopentanamide & 4.15 & 296.21 & 4.66 & 1.46 & 1.82 & 0.01 & $\uparrow$ \\
\hline \multicolumn{8}{|l|}{ Vitamins } \\
\hline Pantothenic acid & 1.831 & -0.945 & 55.4 & 3.378 & 1.397 & 0.003 & $\uparrow$ \\
\hline
\end{tabular}

a VIP and P values: All differential metabolites ART group/CON group were those with a VIP $>1$ and $\mathrm{P}<0.05$

${ }^{b}$ FC: fold change, the ART group vs the CON group 


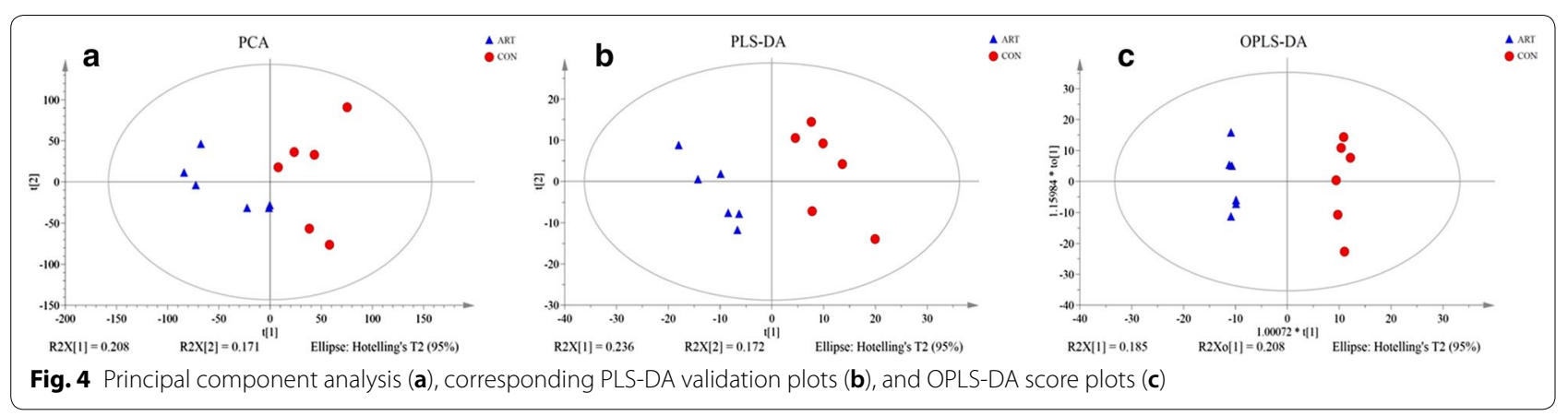

Table 5 Metabolic pathways and metabolites enriched in the ART group compared with the CON group

\begin{tabular}{llll}
\hline Pathway name & Class & Metabolite & P value \\
\hline $\begin{array}{l}\text { Alpha-linolenic acid metabolism } \\
\text { Linoleic acid metabolism }\end{array}$ & Lipid metabolism (2) & LysoPC(18:0), PC(16:0/20:4(5Z,8Z,11Z,14Z)) & 0.01 \\
$\begin{array}{l}\text { Glycerophospholipid metabolism } \\
\text { Lysine degradation }\end{array}$ & Amino acid metabolism (2) & & \\
$\begin{array}{l}\text { Beta-alanine metabolism } \\
\text { Starch and sucrose metabolism }\end{array}$ & Carbohydrate metabolism (1) & 5-Aminopentanamide, Pantothenic acid & 0.05 \\
$\begin{array}{l}\text { Pantothenate and CoA biosynthesis } \\
\text { Zeatin biosynthesis }\end{array}$ & Metabolism of cofactors and vitamins (1) & Maltose & Pantothenic acid \\
Carbohydrate digestion and absorption & Metabolism of terpenoids and polyketides (1) & Adenine & 0.05 \\
Vitamin digestion and absorption & Digestive system (2) & Pantothenic acid; Maltose & 0.03 \\
\hline
\end{tabular}

In the class column, the number in () is the number of metabolites in that class

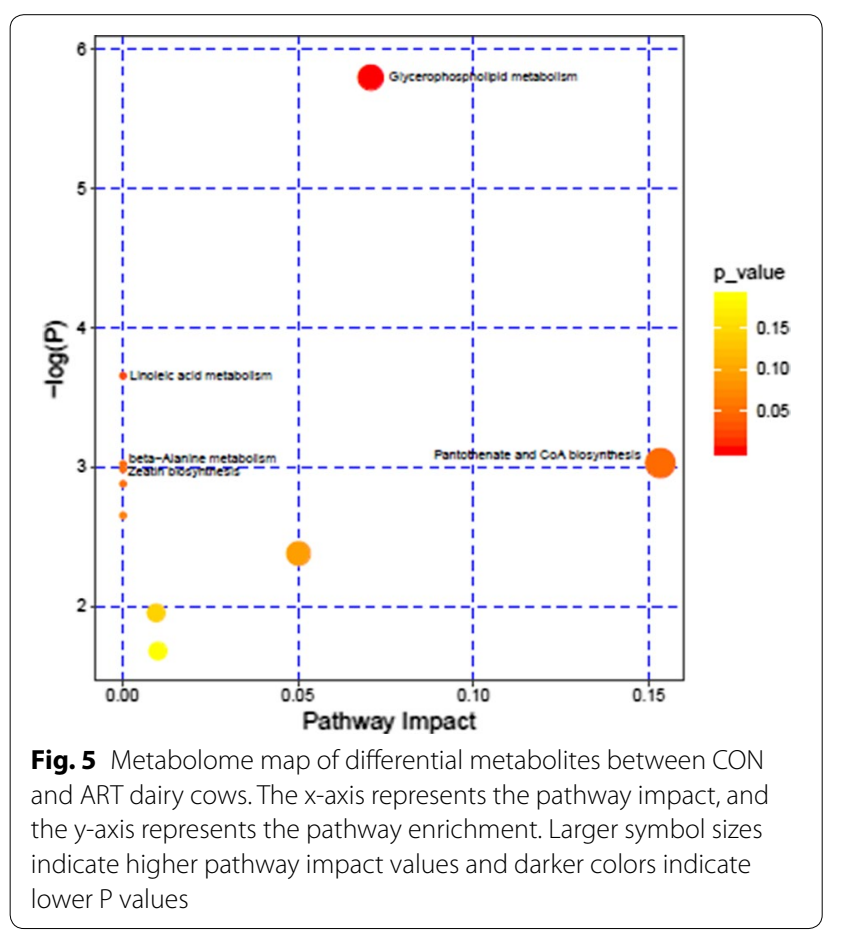

metabolite profiles $(r>0.5$ or $<-0.5, P<0.05)$. Figure 6 also shows that the correlations between both the presence and functions of metabolites and flora in milk are strong. We also found that Rhodococcus, Escherichia-Shigella, Facklamia, Aerococcus, Staphylococcus and Ignavigranum were remarkably correlated with the majority of metabolites (Fig. 6). Of these bacteria, Staphylococcus, Aerococcus and Ignavigranum were significantly positively correlated with $\operatorname{PS}(20: 5(5 Z, 8 Z, 1$ $1 Z, 14 Z, 17 Z) / 18: 2(9 Z, 12 Z)$ ) but negatively correlated with isovitexin 7-(6'"-sinapoylglucoside) $4^{\prime}$-glucoside and 6"-p-coumaroylprunin. Furthermore, the significantly decreased metabolite phosphatidylcholine (PC) (18:0/20:4(5Z,8Z,11Z,14Z)) was positively correlated with Aerococcus, Globicatella, Ignavigranum and Kocuria. The sphingomyelin (SM)(d18:1/14:0) metabolite was significantly correlated with most members of the microbiota. In addition, 1-monopalmitin was negatively correlated with Globicatella and Aerococcus but positively correlated with Escherichia-Shigella, Pseudomonas and Rhodococcus. Overall, we found that milk bacteria were associated with significantly altered metabolites 


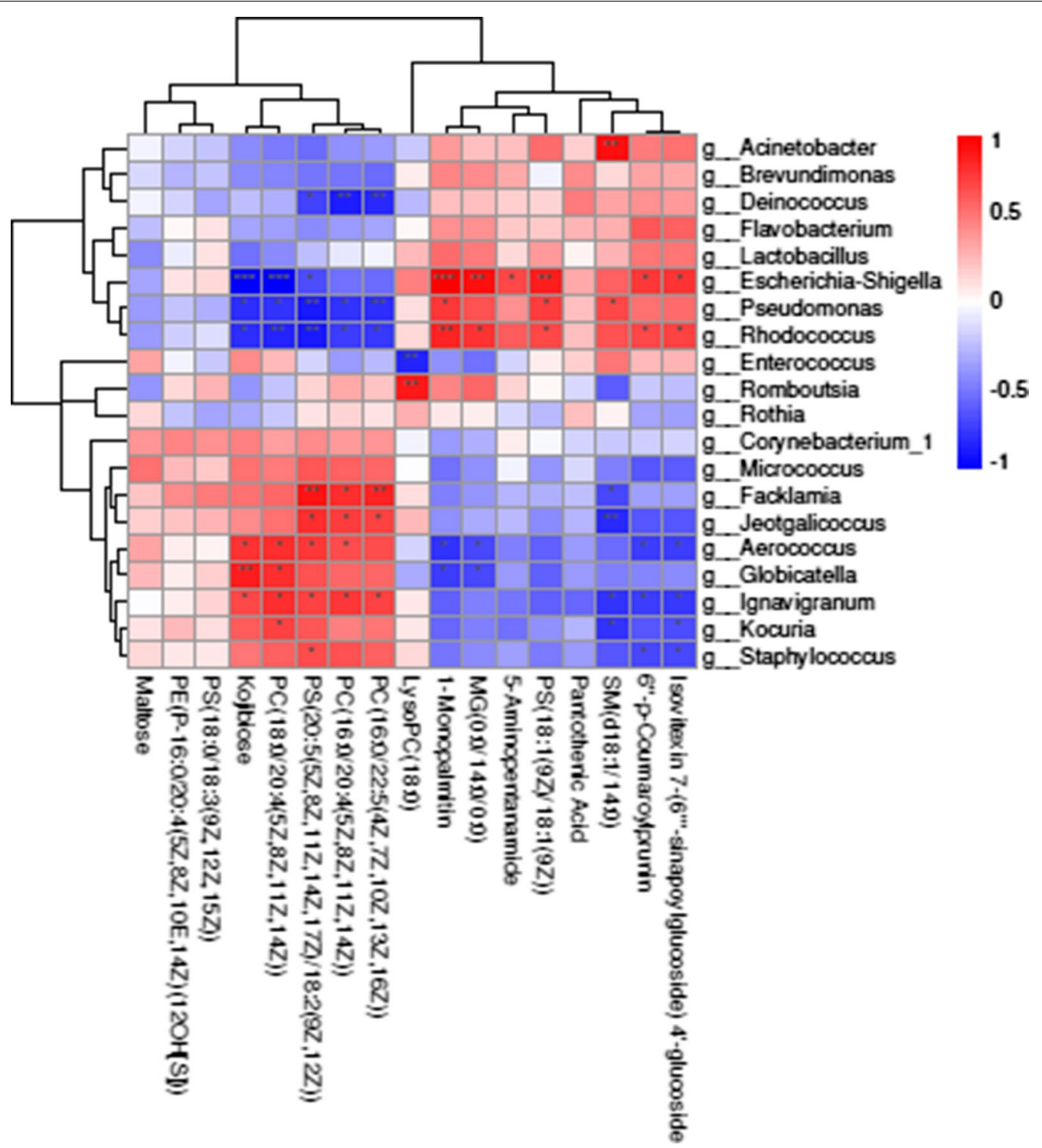

Fig. 6 Correlation analyses between bacterial genera and metabolites in the two treatments. $\left({ }^{*} 0.01<P<0.05 ;{ }^{* *} 0.001<P \leq 0.01 ;{ }^{* * *} P \leq 0.001\right)$

in response to ART extract function, especially some metabolites involved in glycerolipid and flavonoid metabolism.

\section{Discussion}

In this study, we used 16S rRNA and LC-MS metabolomics to compare milk bacteria and metabolites, revealing that ART moderately increased milk production and milk fat content and tended to decrease the SCC at the end of the treatment. Although there was no significant difference in the bacterial diversity (Shannon and Simpson indexes) between the ART and CON groups, the bacterial community richness (ACE and Chao indexes) was significantly lower in the ART group. In addition, the phylum abundances showed that Firmicutes was significantly decreased, while Proteobacteria was higher after treatment with ART. The well-recognized functional data of the milk microbiota can be used not only to identify the quality of milk but also to judge the health status of dairy cow mammary glands (Mansor 2012; Sun et al. 2017a). Correlation analysis of the microbiota and metabolites in milk revealed changes in Aerococcus, Facklamia, and Staphylococcus-related metabolites. Those identified metabolites could cause the differences in milk components between the groups. Thus, we propose that ART activities affect the organism in terms of its milk 
microbiota and metabolites, in turn triggering milk fat changes.

\section{Milk synthesis}

In the present study, ART supplementation moderately increased milk yield and significantly increased milk fat rate. In line with a previous study, adding Artemisia annua to the cow diet increased milk production, which was attributed to the activity of phenols and flavonoids in Artemisia annua (Ferreira et al. 2011; Zhan et al. 2017). Furthermore, it has also been reported that plant flavonoids can increase the acetic acid concentration of dairy cows (Broudiscou et al. 2000). It is well known that acetic acid is the main precursor for milk fat synthesis; similarly, cow milk fat production can be significantly increased by intravenous acetic acid injection (Storry and Rook 1965). Therefore, milk fat increase might be caused by rumen acetate acid changes, which warrants further investigation in future studies.

In addition, the SCC tended to decrease in the ART group compared with the $\mathrm{CON}$ group. The $\mathrm{SCC}$ is one of the most useful and widely used tools to predict mammary gland health in bovines (Tong et al. 2019); thus, our results proved that ART could reduce mastitis susceptibility. Similar to the results of previous studies by Zhan et al. (Zhan et al. 2017), feeding $60 \mathrm{mg} / \mathrm{kg}$ alfalfa flavones could reduce the SCC, alter the composition of milk, improve antioxidant properties and affect immunity in dairy cows. In addition, members of the microbiota such as corynebacteria in milk are usually associated with lowSCC intramammary infections (IMIs) (Guan et al. 2014). Accordingly, the ART antimicrobial and anti-inflammatory properties function by inhibiting the synthesis of cell walls and membranes, interfering with enzymes in or on specific cells and inhibiting bacterial proliferation that causes mastitis in dairy cows (Cushnie and Lamb 2011), especially when modulating the rumen or gut microbiota (Amaretti et al. 2015; Zhan et al. 2017). Similar results were also obtained in our study; the relative abundance of Firmicutes was significantly decreased with ART supplementation, whereas that of Proteobacteria was significantly increased. These species are similar to members of the rumen microbiome (Wang et al. 2018), and we hypothesize that the bacteria can be transferred from the rumen to the mammary gland. Therefore, ART may be associated with a systemic and local immune responsiveness of the udder that is accompanied by microbiota changes.

\section{Multivariate analysis of milk}

16S rRNA sequencing and analysis provide a low-cost and high-yield method for the evaluation of milk microflora (Caporaso et al. 2011; Hélène et al. 2016). In the present study, milk microbial richness was significantly decreased in the ART group. Recent investigations of the bovine milk microbiota show that it usually has a variety of bioactive or probiotic properties to resist the defense mechanism of the udder (F et al. 2016). Additionally, the effect of plant bacteriostatic factors on the rumen microbiota or pathogens of mastitis in dairy cows (Durmic et al. 2008; Cushnie and Lamb 2011) may also be associated with milk microbiota changes in the present study. Similarly, antimicrobials could reduce the diversity of microbial ecosystems and, in alternative stable forms, accompany this with reduced species richness (Lozupone and Knight 2006). Henderson et al. (Henderson et al. 2013) also reported that sample extraction may also affect DNA quality and impact microbiota diversity. Moreover, previous research found that milk microbial diversity was related to mastitis (Hélène et al. 2016). Therefore, no difference in microbiota diversity was caused by the ART treatment, which will strengthen the use of ART as novel prophylactic or therapeutic product (or both) alternatives to antimicrobials in dairy cows.

In our current study, Firmicutes, Proteobacteria, Actinobacteria and Bacteroidetes were the major phyla in the milk of the two groups, and the predominant genera were Aerococcus, Corynebacterium_1, Staphylococcus and Enterococcus, which is consistent with previous studies (Zhang et al. 2017). Similar results were also obtained in the current study; Firmicutes was significantly decreased with ART supplementation, whereas Probacteria was significantly increased. These species are similar to those in the rumen microbiome (Jinjin et al. 2018; Wang et al. 2018). Furthermore, recent reports support this enteromammary pathway via lymphatic and peripheral blood circulation in humans and mice (Rodríguez, 2014) via transfer from mothers to neonates by the gut-breast axis (Jost et al. 2014).

It has been shown that mastitis in cows or goats by Staphylococcus (Guan et al. 2014) causes serious losses in dairy products and to the animal husbandry industry (Tong et al. 2019). Increases in the relative abundances of Corynebacterium boris, Aerococcus and Staphylococcus increase the SCC in the milk of dairy cows (Hogan et al. 1988; Sun et al. 2017b). Furthermore, the contents of Corynebacterium, Facklamia and Aerococcus were higher in dairy cows with a history of clinical mastitis than in healthy dairy cows (Hooman et al. 2018). These pathogens can be found in healthy dairy cows because they are an important cause of mastitis when the proportions of bacteria are out of balance (Guan et al. 2014). In our study, the Staphylococcus, Corynebacterium and Aerococcus abundances were extremely reduced in the milk from the ART group; these genera were the most commonly identified genera omnipresent in the dairy environment 
and gained great attention as the leading bacteria in IMI (Pyrl and Taponen 2009; Vanderhaeghen et al. 2014; Hooman et al. 2018). Our study also detected that Pseudomonas was negatively correlated with most metabolites associated with the ART treatment. (Figure 6). It has been reported that Pseudomonas causes milk deterioration by producing lipase and proteolytic enzymes, and the quality of milk can be maintained by controlling its growth (Chikage et al. 2018). When the lipase content increased, the hydrolysis of triglycerides in dairy cows and long-chain fatty acid production increased. These mechanistic insights into the microbiota response to ART may have important implications for understanding how the milk microbiota participates in biosynthesis regulation and in relation to udder health and mastitis.

\section{Differences in milk metabolites}

Metabolomics is an emerging area of research involving organisms; its methods detect small molecular metabolites in samples and enable a comprehensive understanding of biological processes (Sun et al. 2017a). We used LC-MS to analyze the milk metabolite response to ART supplementation. In total, 35 different metabolites were identified between the ART and $\mathrm{CON}$ groups. Some metabolites were upregulated, such as glycerolipids (MG(0:0/14:0/0:0)), flavonoids (isovitexin 7-(6'”-sinapoylglucoside) $4^{\prime}$-glucoside and 6"-p-coumaroylprunin), carboxylic acids and their derivatives (5-aminopentanamide), and vitamins (pantothenic acid). MG is a monoacylglyceride product of triglycerides that regulates liver development and activity (Coleman and Haynes, 1984). In our study, MG was significantly increased (by 2.67-fold) in the ART group, which strengthens the idea that ART could trigger the mammary gland response to milk biosynthesis, and a remarkably negative correlation was found between MG and Aerococcus. Meanwhile, MG is absorbed more easily than other fatty acid derivatives in the intestine; this absorption increases the content of docosahexaenoic acid and increases the antioxidant activity of mouse plasma (Cho et al. 2009). A plausible hypothesis, similar to one previously reported, is that the mechanisms underlying the effects of nutrition on the potential involvement of the microbiota in the microbiome-gut-brain axis (Cryan and O'Mahony, 2011) are worthy of further study.

In the present study, we found that the flavonoids increased the most of all the metabolites, followed by isovitexin 7-(6'"-sinapoylglucoside) $4^{\prime}$-glucoside (by 3.81 -fold) and $6^{\prime \prime}$-p-coumaroylprunin (by 2.52-fold), in the ART group. These metabolites were negatively correlated with Staphylococcus. Recent studies have shown that flavonoids have antibacterial and antioxidant properties that promote the production and quality of animal products (Zhan et al. 2017). Furthermore, flavonoids increase the activity of antioxidant enzymes to enhance antioxidant capacity and protect tissues and cells from free radical-mediated damage (Xiao-Shuang et al. 2015). These findings may partially explain the moderate SCC decrease induced by ART supplementation. Interestingly, we detected that many metabolites were significantly correlated with members of the microbiota that were potential pathogens, such as Staphylococcus, Facklamia, and Aerococcus. Our findings collectively highlighted the observed microbiota and metabolic changes and provided further insight into the performance of specific ART-related functions in milk profiles that can be used to analyze the differences in milk synthesis between the groups. We speculated that this discrepancy might be associated with the decrease in the SCC resulting from ART supplementation.

PS and PE are important components of biomembrane structure (Cole et al. 2012). The phospholipids in milk are mainly PE, PC and SM (Shoji et al. 2006). PC, which plays a key role in lipid metabolism, can synthesize very low density lipoprotein (VLDL) and be used for the export of triacylglycerol (TAG) in the liver (Cole et al. 2012). Furthermore, aggregation of ATG in the liver may increase fatty liver production (Elke et al. 2016). The current study revealed that PC and PS production was downregulated and PE production was upregulated in the ART group compared with the CON group. Furthermore, the mammary gland utilizes blood PC as a cellular energy source for the production of glycerophosphocholine and free fatty acids and can synthesize milk triglycerides and phospholipids (Easter et al. 1971). Thus, this might explain the mechanism by which the milk fat content was significantly increased in the ART group; specifically, we revealed that glycerophospholipid metabolites were significantly reduced by ART treatment. However, the content of $\mathrm{PC}$ was lower in the $\mathrm{CON}$ group because when the PC breakdown rate decreased, which is closely associated with negative energy balance (NEB) and fat mobilization, causing metabolic disorders and ketosis (Klein et al. 2012). In conclusion, our results indicate that the glycerol phospholipid metabolic pathway may be the main component of the mechanism by which ART affects milk quality.

\section{Key differential metabolic pathways between the two groups}

Based on a comprehensive analysis of important metabolic pathways that identified 33 differential milk metabolites between the two groups, lipid metabolism may be the most important pathway for milk quality improvement induced by ART. An unavoidable NEB accompanies various metabolic disorders and affects the immune 
system, and the energy and lipid metabolism of dairy cows is abnormal and vigorous, causing many diseases (Bouvier-Muller et al. 2018). However, the conversion of PC into milk fat could protect free blood fatty acids, thus reducing the mobilization of body fat (Klein et al. 2012). It is reasonable to conclude that ART protects the health of the body. Furthermore, ART supplementation significantly increased $\beta$-alanine metabolism relative to that of the control group. $\beta$-Alanine metabolism mainly occurs in muscle and brain, and its final metabolite is acetic acid (Griffith 1986). Meanwhile, $\beta$-alanine can improve the antioxidant capacity of the body(Smith et al. 2012), which may be the reason for the improvement in milk quality. In addition, pantothenate and CoA biosynthesis was also significantly upregulated by ART. Pantothenic acid is a water-soluble vitamin. When it is transformed into CoA or bound to acyl carrier protein (ACP) in vivo, it mainly participates in the metabolism of fatty acids, carbohydrates and energy and significantly reduces the levels of cholesterol and triglycerides (Smith and Song 1996). This may reduce abnormalities in lipid and energy metabolism in dairy cows. Therefore, our data indicate that glycerophospholipids and glycerolipids could be potential biomarkers in the milk response to ART feed in dairy cows, which further supports the functional link between ART and milk changes. Taken together, the results in our study support the assumption that ART changes substances in milk by maintaining lipid metabolism in the mammary gland.

In summary, LC-MS and $16 \mathrm{~S}$ rRNA was used to analyze milk metabolomics and bacterial community profiles for dairy cows, revealing that ART supplementation increased milk fat, decreased the SCC and may affect the structures of bacterial communities, metabolites and metabolic pathways. Moreover, ART decreased the relative abundances of Corynebacterium_1, Aerococcus, Staphylococcus and Facklamia. Our results also revealed that some of the 33 metabolites that changed significantly in milk after ART supplementation were potential biomarkers that respond to ART. In addition, glycerophospholipids and glycerolipids could be potential biomarkers in the milk response to ART feed in dairy cows, and ART changes substances in milk by protecting lipid metabolism in the mammary gland. This study has provided further insights into the mechanisms at the metabolic level that can improve understanding of the effects of ART addition. Overall, our findings provide new strategies for improving milk quality with the use of ART; however, they warrant further investigations for identification of potential immune regulation mechanisms underlying the effects of ART on dairy cows.

\section{Supplementary information}

Supplementary information accompanies this paper at https://doi. org/10.1186/s13568-020-01080-w.

Additional file 1. Company qualification and artemisinin analysis certificate.

\section{Acknowledgements}

The authors thank the dairy barn staff for taking care of the cows, especially Kangkang Chu for providing technical assistance. The authors are grateful to Dandan He, from Shanghai Majorbio Bio-pharm Technology Co.,Ltd, for her assistant of the multivariate statistics analysis. Linshu Jiang thanks for the Beijing million Talents Project. Jinjin Tong also thanks the China Postdoctoral Science Foundation and the Beijing Postdoctoral Science Foundation.

\section{Authors' contributions}

$\mathrm{KH}, J J T, \mathrm{HZ}$ and LSJ developed hypothesis, conceived the project and responsible for all data, figures and text. KH, JJT, HZ, HN and SG performed the experiments. $\mathrm{KH}, \mathrm{JJT}$ and $\mathrm{HZ}$ conducted data analysis. $\mathrm{KH}, \mathrm{JJT}$ and $\mathrm{HZ}$ wrote the manuscript. JJT, HZ, YQG, LSJ and BHX revised the paper. All authors read and approved the final manuscript.

\section{Funding}

This study was financially supported by the Project of the National Natural Science Foundation of China (Grant Nos. 31802091, 31702302 and 31772629) and the National Key Research and Development Plan (2016YFD0700205, 2016YFD0700201 and 2017YFD0701604)

\section{Availability of data and materials}

All raw sequences were submitted to the NCBI Sequence Read Archive (SRA: http://www.ncbi.nlm.nih.gov/Traces/sra/) under accession number SRP

254006. The data supporting the conclusion of this article are included in this article.

Ethics approval and consent to participate

All experimental procedures were approved by the Animal Care Committee, Beijing University of Agriculture (Beijing, China).

\section{Consent for publication}

All authors carefully read and agree to be accountable for all aspects of the work.

\section{Competing interests}

The authors declare that they have no competing interests.

\section{Author details}

${ }^{1}$ Beijing Key Laboratory for Dairy Cow Nutrition, Beijing University of Agriculture, Beijing 102206, People's Republic of China. ${ }^{2}$ State Key Laboratory of Animal Nutrition, Institute of Animal Science, Chinese Academy of Agricultural Sciences, Beijing 100193, People's Republic of China.

Received: 5 May 2020 Accepted: 8 August 2020

Published online: 24 August 2020

\section{References}

Addis MF, Tanca A, Uzzau S, Oikonomou G, Bicalho RC, Moroni P (2016) The bovine milk microbiota: insights and perspectives from-omics studies. Mol BioSyst 12(8):2359-2372

Amaretti A, Raimondi S, Leonardi A, Quartieri A, Rossi M (2015) Hydrolysis of the rutinose-conjugates flavonoids rutin and hesperidin by the gut microbiota and bifidobacteria. Nutrients 7(4):2788-2800. https://doi. org/10.3390/nu7042788

Bouvier-Muller J, Allain C, Enjalbert F, Farizon Y, Portes D, Foucras G, Rupp $R$ (2018) Somatic cell count-based selection reduces susceptibility to energy shortage during early lactation in a sheep model. J Dairy Sci 101(3):2248-2259. https://doi.org/10.3168/jds.2017-13479 
Brisibe E, Umoren U, Owai P, Brisibe F (2008) Dietary inclusion of dried Artemisia annua leaves for management of coccidiosis and growth enhancement in chickens. Afr J Biotech 7(22):4083-4092. https://doi.org/10.5897/ AJB08.490

Broudiscou L, Papon Y, Broudiscou A (2000) Effects of dry plant extracts on fermentation and methanogenesis in continuous culture of rumen microbes. Anim Feed Sci Technol. https://doi.org/10.1016/s0377 $-8401(00) 00193-0$

Caporaso J, Lauber C, Walters W, Berg-Lyons D, Lozupone C, Turnbaugh P, Fierer N, Knight R (2011) Global patterns of 16S rRNA diversity at a depth of millions of sequences per sample. Proc Natl Acad Sci USA 108(1):45164522. https://doi.org/10.1073/pnas.1000080107

Chikage T, Yamada K, Takeuchi H, Inokuchi Y, Kashiwagi A, Toba T (2018) A lytic bacteriophage for controlling pseudomonas lactisin raw cows milk. Appl Environ Microbiol 84:e00111-e00118. https://doi.org/10.1128/AEM

Cho K, Lee J, Kim J, Park S, Choi M, Lee Y, Choi I, Lee K (2009) Blood lipid-lowering and antioxidant effects of a structured lipid containing monoacylglyceride enriched with monounsaturated fatty acids in C57BL/6 Mice. Med Food 12(2):452-460. https://doi.org/10.1089/jmf.2007.0693

Cole L, Vance J, Vance D (2012) Phosphatidylcholine biosynthesis and lipoprotein metabolism. Biochim Biophys Acta 1821(5):750-761. https://doi. org/10.1016/j.bbalip.2011.09.009

Coleman R, Haynes E (1984) Hepatic monoacylglycerol acyltransferase. Am Soc Biol Chem 258(14):8934-8938

Cryan J, O'Mahony S (2011) The microbiome-gut-brain axis: from bowel to behavior. Neurogastroenterol Motil 23(3):187-192. https://doi.org/10.111 1/j.1365-2982.2010.01664.x

Cushnie T, Lamb A (2011) Recent advances in understanding the antibacterial properties of flavonoids. Int J Antimicrob Agents 38(2):99-107. https:// doi.org/10.1016/j.jjantimicag.2011.02.014

Durmic Z, Mcsweeney C, Kemp G, Hutton P, Wallace R, Vercoe P (2008) Australian plants with potential to inhibit bacteria and processes involved in ruminal biohydrogenation of fatty acids. Anim Feed Sci Technol. https:// doi.org/10.1016/j.anifeedsci.2007.05.052

Easter D, Patton S, McCarthy R (1971) Metabolism of phospholipid in mammary gland: I The supply of phospholipid for milk synthesis in the rat and goat. Lipids 6(11):844-849. https://doi.org/10.1007/BF02531215

Edgar R (2013) UPARSE: highly accurate OTU sequences from microbial amplicon reads. Nat Methods 10(10):996. https://doi.org/10.1038/NMETH.2604

Elke H, Annabella K, Leonhard G, Qendrim Z (2016) Alterations of the lipid metabolome in dairy cows experiencing excessive lipolysis early postpartum. PloS ONE. https://doi.org/10.1371/journal.pone.0158633

Ferreira J, Luthria D, Sasaki T, Heyerick A (2011) Flavonoids from artemisia annua I as antioxidants and their potential synergism with artemisinin against malaria and cancer. Molecules 15(5):3135-3170. https://doi. org/10.3390/molecules15053135

Ganda E, Gaeta N, Sipka A, Pomeroy B, Oikonomou G, Schukken Y, Bicalho R (2017) Normal milk microbiome is reestablished following experimental infection with Escherichia coli independent of intramammary antibiotic treatment with a third-generation cephalosporin in bovines. Microbiome 5(1):1-17. https://doi.org/10.1186/s40168-017-0291-5

Gowda G, Djukovic D (2013) Overview of mass spectrometry-based metabolomics: opportunities and challenges. Methods Mol Biol 1198(1198):3-12. https://doi.org/10.1007/978-1-4939-1258-2_1

Griffith O (1986) Beta-amino acids: mammalian metabolism and utility as alpha-amino acid analogues. Annu Rev Biochem 55(1):855. https://doi. org/10.1146/annurev.bi.55.070186.004231

Guan L, Oikonomou G, Bicalho M, Meira E, Rossi R, Foditsch C, Machado V, Teixeira A, Santisteban C, Schukken Y, Bicalho R (2014) Microbiota of cow's milk; distinguishing healthy, sub-clinically and clinically diseased quarters. PLoS ONE 9(1):e85904. https://doi.org/10.1371/journal.pone.0085904

Hélène F, Lucie R, Aurélie N, Bouchard D, Jacques L, Philippe L, Jean-Marc A Pierre-Guy M, Le L, Sergine E (2016) Bovine teat microbiome analysis revealed reduced alpha diversity and significant changes in taxonomic profiles in quarters with a history of mastitis. Front Microbiol. https://doi. org/10.3389/fmicb.2016.00480

Henderson G, Cox F, Kittelmann S, Miri V, Zethof M, Noel S, Waghorn G, Janssen P (2013) Effect of DNA extraction methods and sampling techniques on the apparent structure of cow and sheep rumen microbial communities. PLoS ONE 8(9):e74787. https://doi.org/10.1371/journal.pone.0074787
Hogan J, Smith K, Todhunter D, Schoenberger P (1988) Rate of environmental mastitis in quarters infected with Corynebacterium bovis and Staphylococcus Species. J Dairy Sci 71(9):2520-2525. https://doi.org/10.3168/jds. S0022-0302(88)79840-9

Hooman D, Kelsey F, Shadi S, David F, Jeroen (2018) Invited review: microbiota of the bovine udder: Contributing factors and potential implications for udder health and mastitis susceptibility. J Dairy Sci. https://doi. org/10.3168/jds.2018-14860

Hou, K., Tong T., Chu, K., Xiong, B., and Jiang, L. 2019. Effects of Bamboo Leaf Flavonoids and Artemisia annua Extract on Milk Performance, Millk Somatic Cell Count and Serum Immune and Antioxidant Related Indexes of Dairy Cows with Subclinical Mastitis. Chinese Journal of Animal Nutrition 9:4286-4295. http://en.cnki.com.cn/Article_en/CJFDTotal-DWYX2 01909043.htm

Jinjin T, Hua Z, Delian Y, Yonghong Z, Benhai X, Linshu J (2018) Illumina sequencing analysis of the ruminal microbiota in high-yield and low-yield lactating dairy cows. PLoS ONE 13(11):e198225. https://doi.org/10.1371/ journal.pone.0198225

Jost T, Lacroix C, Braegger C, Rochat F, Chassard C (2014) Vertical motherneonate transfer of maternal gut bacteria via breastfeeding. Environ Microbiol 16(9):2891-2904. https://doi.org/10.1111/1462-2920.12238

Junza A, Saurina J, Barrón D, Minguillón C (2016) Metabolic profile modifications in milk after enrofloxacin administration studied by liquid chromatography coupled with high resolution mass spectrometry. J Chromat A. 1460:92-99. https://doi.org/10.1016/j.chroma.2016.07.016

Klein M, Buttchereit N, Miemczyk S, Immervoll A, Louis C, Wiedemann S, Junge W, Thaller G, Oefner P, Gronwald W (2012) NMR metabolomic analysis of dairy cows reveals milk glycerophosphocholine to phosphocholine ratio as prognostic biomarker for risk of ketosis. J Proteome Res 11(2):13731381. https://doi.org/10.1021/pr201017n

Kolde, R. 2015. pheatmap: Pretty Heatmaps. http://ie.archive.ubuntu.com/ CRAN/web/packages/pheatmap/

Korhonen H, Marnila P, Gill H (2000) Milk immunoglobulins and complement factors. Br J Nutr 84(S1):75-80. https://doi.org/10.1017/S00071145000022 82

Kuehn J, Gorden P, Daniel M, Rong R, Dong Q, Plummer P, Chong W, Phillips G, Willem V (2013) Bacterial community profiling of milk samples as a means to understand culture-negative bovine clinical mastitis. PLOS ONE 8(4):e61959. https://doi.org/10.1371/journal.pone.0061959

Lozupone C, Knight R (2006) UniFrac: a new phylogenetic method for comparing microbial communities. Appl Environ Microbiol 71(12):8228-8235. https://doi.org/10.1128/AEM.71.12.8228-8235.2005

Mansor R. 2012. Proteomic and metabolomic studies on milk during bovine mastitis. University of Glasgow http://theses.gla.ac.uk/id/eprint/3207

Orth R (1992) Sample day and lactation report. DHIA 200. Fact Sheet A-2. MidStates Dairy Records Processing Center (DRPC) Ames, IA1992

Pyrl S, Taponen S (2009) Coagulase-negative staphylococci-emerging mastitis pathogens. Vet Microbiol 134(1-2):3-8. https://doi.org/10.1016/j.vetmi c.2008.09.015

Rodríguez J (2014) The origin of human milk bacteria: is there a bacterial entero-mammary pathway during late pregnancy and lactation? Adv Nutri 5(6):779-784. https://doi.org/10.3945/an.114.007229

Shi C, Li H, Yang Y, Hou L (2015) Anti-Inflammatory and immunoregulatory functions of artemisinin and its derivatives. Mediators Inflamm. https:// doi.org/10.1155/2015/435713

Shoji H, Shimizu T, Kaneko N, Shinohara K, Yamashiro Y (2006) Comparison of the phospholipid classes in human milk in Japanese mothers of term and preterm infants. Acta Paediatr 95(8):996-1000. https://doi. org/10.1080/08035250600660933

Smith C, Song W (1996) Comparative nutrition of pantothenic acid. J Nutr Biochem 7(6):312-321. https://doi.org/10.1016/0955-2863(96)00034-4

Smith A, Stout J, Kendall K, Fukuda D, Cramer J (2012) Exercise-induced oxidative stress: the effects of $\beta$-alanine supplementation in women. Amino Acids 43(1):77-90. https://doi.org/10.1007/s00726-011-1158-x

Song Z, Cheng K, Zhang L, Wang T (2017) Dietary supplementation of enzymatically treated Artemisia annua could alleviate the intestinal inflammatory response in heat-stressed broilers. J Therm Biol 69:184-190. https:// doi.org/10.1016/j.jtherbio.2017.07.015

Storry J, ROOK J (1965) Effect in the cow of intraruminal infusions of volatile fatty acids and of lactic acid on the secretion of the component fatty 
acids of the milk fat and on the compostion of blood. Biochem J 96:210-217. https://doi.org/10.1042/BJ0970609_b1b

Sun H, Kai S, Wu X, Xue M, Wei Z, Liu J, Liu H (2017a) Lactation-related metabolic mechanism investigated based on mammary gland metabolomics and 4 biofluids' metabolomics relationships in dairy cows. BMC Genomics 18(1):936-948. https://doi.org/10.1186/s12864-017-4314-1

Sun M, Gao J, Ali T, Yu D, Zhang S, Khan S Fanning, Han B (2017b) Characteristics of Aerococcus viridans isolated from bovine subclinical mastitis and its effect on milk SCC, yield, and composition. Trop Anim Health Prod 49(4):843-849. https://doi.org/10.1007/s11250-017-1271-2

Tong J, Zhang H, Zhang Y, Xiong B, Jiang L (2019) Microbiome and metabolome analyses of milk from dairy cows with subclinical Streptococcus agalactiae mastitis-potential biomarkers. Front Microbiol 10:2547. https:// doi.org/10.3389/fmicb.2019.02547

Vanderhaeghen W, Piepers S, Leroy F, Coillie E, Haesebrouck F, Vliegher S (2014) Invited review: effect, persistence, and virulence of coagulase-negative Staphylococcus species associated with ruminant udder health. J Dairy Sci 97(9):5275-5293. https://doi.org/10.3168/jds.2013-7775

Wang K, Nan X, Chu K, Tong J, Yang L, Zheng S, Zhao G, Jiang L, Xiong B (2018) Shifts of hydrogen metabolism from methanogenesis to propionate production in response to replacement of forage fiber with non-forage fiber sources in diets in vitro. Front Microbiol 9:2764. https://doi.org/10.3389/ fmicb.2018.02764
Xiao-Shuang, S., Zhan, J., Zhan, K., Liu,M., and Zhao, G. 2015. Proliferation stimulus and antioxidant effect of alfalfa flavonoids on dairy cow mammary epithelial cells cultured in vitro. Acta Prataculturae Sinica http:// en.cnki.com.cn/Article_en/CJFDTotal-CYXB201512016.htm

Xue, M., Jiangwen, X., Jizeng,H., and Zhou, Z. 2004. Pharmacokinetics of dihydroartemisnine of the active metabolite of artesunate in cows and cattle. Chinese Journal of Veterinary Drug (7):4-6. http://en.cnki.com.cn/Artic le_en/CJFDTOTAL-ZSYY200407000.htm

Zhan J, Wu C, Liu M, Su X, Zhan K, Zhang C, Zhao G (2017) Effects of alfalfa flavonoids on the production performance, immune system, and ruminal fermentation of dairy cows. Asian Aust J Anim Sci 30(10):1416-1424. https://doi.org/10.5713/ajas.16.0579

Zhang F, Wang Z, Lei F, Wang B, Jiang S, Peng Q, Zhang J, Shao Y (2017) Bacterial diversity in goat milk from the Guanzhong area of China. J Dairy Sci 100(10):7812-7824. https://doi.org/10.3168/jds.2017-13244

\section{Publisher's Note}

Springer Nature remains neutral with regard to jurisdictional claims in published maps and institutional affiliations.

\section{Submit your manuscript to a SpringerOpen ${ }^{\circ}$ journal and benefit from:}

- Convenient online submission

- Rigorous peer review

- Open access: articles freely available online

- High visibility within the field

- Retaining the copyright to your article

Submit your next manuscript at $\boldsymbol{\nabla}$ springeropen.com 